International Journal of Linguistics, Literature and Translation (IJLLT)

ISSN: 2617-0299 (Online); ISSN: 2708-0099 (Print)

DOI: $10.32996 / \mathrm{ijllt}$

Journal Homepage: www.al-kindipublisher.com/index.php/ijllt

\title{
Inflectional Forms of Tense in Lutsotso
}

Hellen Odera ${ }^{1 *}$, David Barasa ${ }^{2}$ and Atichi Alati ${ }^{3}$

${ }_{123}$ Masinde Muliro University of Science and Technology, Kenya

Corresponding Author: Hellen Odera, E-mail: hellenselah@gmail.com

\section{ARTICLE INFORMATION}

Received: November 20, 2020

Accepted: January 10, 2021

Volume: 4

Issue: 1

DOI: 10.32996/jillt.2021.4.1.3

\section{KEYWORDS}

Verb, Tense, Lutsotso, Bantu,

Subject verb markers

\section{ABSTRACT}

Lutsotso verbs consist of more than one morpheme expressing a particular grammatical meaning. The various morphological affixes attached to the verb indicate agreement, tense, aspect and voice. Tense and aspect morphemes in Lutsotso follow the same order for all types of verb constructions. Although tense and aspect in Lutsotso are deeply intertwined, this paper focuses on tense only. The Lutsotso tense is divided into the present, past and the future. The past and the future are distributed in four degrees as follows: remote, intermediate, near and immediate. Since the verb is the unit of analysis in this paper, we first describe the basic verb form in Lutsotso. This will entail the verb root and other crucial aspects such as the final vowel and the infinitive form that influence it. We also give agreement in the feature, person, number, subject verb markers and object markers. Finally, tense forms in Lutsotso will be discussed beginning with the present, followed by the past and the future.

\section{Introduction}

This paper analyzes the Lutsotso verb inflection. Lutsotso is a dialect of the Oluluhya language which belongs to the Niger Congo family, Bantu, Masaba (E.32) (Eberhard et al., 2020). It is spoken by the Batsotso people who live in Kakamega County. The area inhabited by the Batsotso is divided into five: Butsotso North, Butsotso South, Butsotso East, Butsotso West and Butsotso Central. The population of Lutsotso speakers found in Kakamega County was estimated to be 162,822 as contained in the 2020 report of the Kenya National population census carried out in 2019. The Oluluhya dialects that neighbour Batsotso are: Luisukha, Luidakho, Lukisa, Luwanga, Lunyala (North) and Lukabras.

Angogo (1983) and Sikuku (1998) have observed that Bantu languages are agglutinative in structure. Lutsotso, like other Bantu languages, manifests the typical Bantu agglutinative structure. The verb is of great importance since it comprises a complete sentence on its own when inflected for person, tense, aspect, mood, number, and agreement.

Tense is a grammatical category that relates to time (Trask, 1999, p. 207). Each language is capable of communicating time's infinite variations. If a language in its grammar constructs these time distinctions, then it has the tense category. In its morphology, Lutsotso has the tense category labelled. Consequently, Lutsotso uses verb inflection to encode tense. It also makes use of optional time adverbials such as mumaßweßwe 'morning', hamukoloßa 'evening' to emphasize specific time being referred to.

This paper will explore the following areas: Firstly, it will look at the verb root which forms the nucleus of the verb structure in Lutsotso. Then, it will discuss the infinitive which forms the stem of the verb followed by agreement features. These features must also agree with the object NP in cases where the verb inflects for an object marker. This will be followed by a discussion on Lutsotso pronouns and the morphological configurations of tense in Lutsotso.

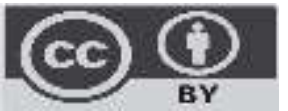

Published by Al-Kindi Center for Research and Development. Copyright (c) the author(s). This open access article is distributed under a Creative Commons Attribution (CC-BY) 4.0 license 


\section{The Lutsotso Toor}

The root of the verb, usually called the verb radical in Bantu studies, is the form that remains when all inflectional and derivational affixes have been removed (Kioko, 2005, p. 2). This, thus, makes it not easy to carry meaning in isolation until when various affixes are added to it. The verb root (VR) in Lutsotso, just like in many other languages, form the nucleus of the verb structure. Since the root is bound, it requires the final vowel (FV) suffix for complete meaning as illustrated in example 1 below:

1) a. rem-
VR
'cut'
VR-FV
'cut'

b. rem-a

The root in (1a) above cannot make sense on its own. Example (1b) makes sense because the final vowel has been added to the root.

Typically, the majority of verb roots in Lutsotso have the structure CVC as with /rem/ 'cut' in (1) and as illustrated in (2) below.

2) CVC

Lim-a

VR-FV

'Dig'

In example 2 above, lim- 'dig' is the verb root taking the structure CVC and /-a/ is the final vowel. The final vowel /-a/ usually marks the subjunctive and imperative mood. The examples below show the two forms of the final vowel representing the subjunctive and imperative mood.

3) a. o-remul-e

$$
\begin{aligned}
& \text { 2SG-slash-SBJV } \\
& \text { 'that you may slash' } \\
& \text { b. remul-a } \\
& \text { 3SG slash-IMP } \\
& \text { 'Slash' } \\
& \text { c. m-remul-e } \\
& \text { 3PL-slash-IMP } \\
& \text { 'They slash' (plural) }
\end{aligned}
$$

The final vowel /-e/ in (3a) marks the subjunctive while /-a/ mark the imperative mood in singular and plural, respectively. The subjunctive is used to express a suggestion, a necessity or an indirect command/order while the imperative mood is the attitude on the part of the speaker towards the factual content of the utterance (Crystal, 1980, p. 247). The subjunctive is considered as a more polite form of the imperative (Appleby, 1961, p. 68). 


\section{The infinitive}

The infinitive is a term for the form of a verb that is unmarked for person, tense, aspect, mood or concordial agreement. In other words, it is the basic form of a verb. The infinitive is the base form of a word (Payne, 1986, p. 156). In Lutsotso the infinitive form of the verb is formed by prefixing ' $x u$-' $/ u x u$ - to the stem of the verb. It is important to take note that the subject marker and the infinitive in Lutsotso do not co-occur. Consider the examples below:

4) a. oxu-kon-a

$$
\begin{aligned}
& \text { INF-VR-FV } \\
& \text { 'to sleep' } \\
& \text { b. xu-ßay-a } \\
& \text { INF-VR-FV } \\
& \text { 'to play' }
\end{aligned}
$$

In examples (4a) and (4b), the infinitive oxu- and $x u$ - is prefixed to the root '-kon-' in '4a' and ' $\beta a y$ ' in '4b' respectively. The verb root has the final vowel '-a' as its suffix.

\section{Agreement}

Riemsdijk and Williams (1986) define agreement (AGR) as a set of features including specifications for gender, number and person. In Lutsotso, these features must agree with the subject NP and are eventually realized on the verb. These features must also agree with the object NP in cases where the verb inflects for an object. Osore (2017) observes that in Lutsotso, sentence constituents are brought into grammatical agreement by morphemes which inflect on the verb and which represent or carry the features of the subject or object where the NP could either be a noun or a pronoun. In this paper, these two morphemes are referred to as subject marker (SM) and object marker (OM). AGR manifests the features number, class and person (in cases of personal pronouns) of lexical NPs. The NP, that is, the subject of a verb must agree in number class and person with the inflected

\begin{tabular}{|c|c|c|c|c|}
\hline Class & Nominal prefix & Verb prefix & Example & Gloss \\
\hline 1. & omu- & a- & $\begin{array}{l}\text { omusiani, } \quad \text { omundu, } \\
\text { omukhana }\end{array}$ & person \\
\hline 2. & aba- & ba- & abandu & people \\
\hline 3. & omu- & ku- & omusaalu & tree \\
\hline 4. & emi- & chi- & omisaala & trees \\
\hline 5. & li- & li- & linyonyi & bird \\
\hline 6. & ama- & ka- & amanyonyi & birds \\
\hline 7. & eshi- & shi- & eshifumbi & chair \\
\hline 8. & ebi- & bi- & ebifumbi & chairs \\
\hline 9. & $\mathrm{i}(\mathrm{n})$ & yi- & imbusi, ing'ombe & goat, cow \\
\hline
\end{tabular}
$\mathrm{SA}$ in the verb. Likewise, the object NP must agree with the OM.

The Lutsotso language has twenty noun classes (Osore 2009). They determine the verbal prefix to be used and the form of the final vowel on the verb stem. Table 1 below shows the noun classes in Lutsotso.

\section{Table 1: Lutsotso noun classes}




\begin{tabular}{|c|l|l|l|l|}
\hline 10. & tsi & tsi & tsimbusi, tsing'ombe & goats, cows \\
\hline 11. & olu & lu & olusaala & stick \\
\hline 12. & tsi & tsi & tsisaala & sticks \\
\hline 13. & akha & kha & akhaana & tiny baby \\
\hline 14. & oru & ru & orwana & tiny babies \\
\hline 15. & obu & bu/bw & obusuma & ugali \\
\hline 16. & okhu & Khu & okhulima & to dig \\
\hline 17. & ha & ha & hango & at home \\
\hline 18. & $\mathrm{u}$ & $\mathrm{mu}$ & munzu & in the house \\
\hline 19. & khu & khu & khunzu & on the house \\
\hline 20. & oku & ku & okundu & very big person \\
\hline
\end{tabular}

\section{Source: Osore, 2009, p. 33}

From class $1-14,20$ pairs differ in singular and plural, this is because nouns in these classes are countable nouns. Class 15 (obuclass) consists of abstract nouns such as oßuheli 'love' and collective nouns such as oßusuma (ugali) which are found in the singular form only. Class 16 consists of verbs in the infinitive form when they are used as nouns in sentences. For example, the verbs oxulima 'to dig' and oxweya 'to sweep' function as nouns as illustrated in the following sentences:

5) a. oxulima khu reranga efiaxulia

'Digging brings food'

b. oxweya xhu tnyiye aba:na

'Sweeping has made the children tired'

Class 17, 18 and 19 are locative prefixes which act as prepositions in Lutsotso. Therefore, these prefixes do not mark number. We also note that omu- prefix of class I and class 3 look alike. The difference is that they do not share the same concord prefixes as shown in Table 1 above. Concord prefix for class 1 is $u$ - while the concord prefix for class 3 is $k u$-. The noun morphology influences the verb morphology as observed above, the noun classes determine the verbal prefix to be used and the form of the final vowel in relation to tense, aspect and mood.

\subsection{The Personal Pronoun}

The Lutsotso personal pronoun can occur as heads of noun phrases thus substituting whole NPs. When the personal pronoun co-occurs with the subject NP and is prefixed to the verb it functions as a subject agreement marker. The personal pronouns in Lutsotso are as follows:

\section{Singular forms}

The pronoun

\section{Plural forms}

\begin{tabular}{|c|c|c|c|c|}
\hline $1^{\text {st }}$ & $2^{\text {nd }}$ & $3^{\text {rd }}$ & $1^{\text {st }}$ & $2^{\text {nd }}$ \\
\hline sie & ewe & je & efwe & enwe \\
\hline me) & (you) & (he, she) we, us & you & they $\mathrm{tr}$ \\
\hline
\end{tabular}


6) a. je je-na

1 Pron 3SG-wants

b. je-na

3SG-wants

'He/she wants'

In example (6a), je- is prefixed to - $n a$ 'want' and it function as a concordial marker. The personal pronoun je in example (6b) is prefixed to the verb -na 'want' and it specifies that the subject has the feature (+ singular) this subject in this case is optional.

4.2 Agreement in class gender/number

The class of the subject or object in Lutsotso is an important feature that is shown in agreement. The agreement marker must reflect the class to which the NP belongs. In most cases, the AGR marker is usually the class prefix of the NP it denotes. Agreement in the features number and class can be illustrated as shown in (7) below:

Noun $\quad$ AGR in the verb

7)

a. omwa-ana

a-la-tsi-a

SG-baby

3SG-FUT-go-FV

'baby'

Class one

Class one

b. aßa-ana (babies)

ßa-la-tis-a

PL-baby

3PL-FUT-go-FV

Class two

Classes two

In (7) above, the nominal root -ana is given a number specification by the prefix 'a' in singular form and ' $\beta a$ ' for plural form which are the subject agreement markers on the verb. Omwa- and aßa- are subject agreement markers on the noun.

\subsection{Subject Marking}

Person and number are integrated inflectional categories on the verb representing an overt subject in Lutsotso verbal form. The subject position of a Lutsotso sentence can be occupied by either a noun or a pronoun. This is observed in the subject marker on the verb which reflects person and number of the overt subject. The noun morphology interacts with the verb morphology to make tense possible since the subject of a verb must agree in number, class and person with the inflected SM in the verb. The subject marker on the verb therefore expresses subject incorporation in the verbal form. In other words, the subject marker copies the features of the nominal subject onto the verb morphologically so that these features (person and number) - for instance ' $a$ ' is used for singular subjects with the feature specification [+ human] while [i] is used for singular subjects with the feature [-human] as seen in (8) below;

8) a. Senfe a-la-tsi-a xu-kanisa

3SG:aunt 3SGSM-FUT-go-FV INF-church

'aunt will go to church' 


$$
\begin{array}{lrr}
\text { b. } \quad \text { imßwa } \quad \text { i-la-li-a } & \text { i-nyama } \\
\text { 3SG:dog } & \text { 3SG-FUT- eat -FV }
\end{array}
$$

'The dog will eat meat'

In (8a), the agreement marker is 'a-' because the subject senje 'aunt' has the feature specification [+ human]. In (8b) the agreement marker is ' $\mathrm{i}$-' because the subject imbwa 'dog' has the feature specification [-human]

The feature person is only associated with class one and two nouns and it represents the human nominal subject in the verb. Three persons are distinguished in Lutsotso. They are, first second and third person. The person agreement marker exists as a bound morpheme prefixed on the main verb. Agreement in the feature person in Lutsotso is best illustrated by use of personal pronouns as in (9):

9) a. nda-soma

1SG:PST-read

'I read'

b. xwa-soma

1PL:PST-read

'We read

c. o-soma

2SG:PRS -read

'He/She read'

d. ja-soma

3SG:PST-read

'He/she read'

In (9a), nda - is the subject agreement marker attached to the verb soma 'read' while in (9b) the agreement marker is $x w a-$ and is attached to the verb soma 'read'. In (9c) and (9d) have the subject agreement markers $o-$ and ja- respectively, attached to the verb soma 'read' It is also important to note that the subject marker on the verb also reflects person, tense and number of the overt subject.

\subsection{The object markers}

In Lutsotso, the object marker is prefixed to the verb root to denote a covert object in a syntactic structure. The object position in Lutsotso can be occupied by a noun or a pronoun. It occurs as a prefix immediately before the verb root. Like the subject marker, the object marker copies the features of the noun phrase on the verb as illustrated in (10) below:

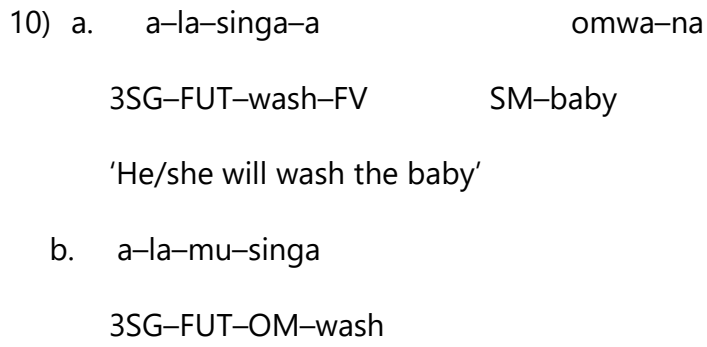


'He/she will wash him/her'

${ }^{*}$ C. a-la-mu-sing-a omwa-na

3SG-FUT-OM-FV-wash SM-baby

'He/she will him/her wash the baby'

In (10b), the object marker is mu- and it occurs immediately before the verb root singa (wash). There appears to be a rule governed relationship between the object marker (morpheme) and the nominal object in terms of their distributional properties. Unlike the subject marker and its nominal subject which may both be present, the object marker and its nominal object cannot co-occur in the same sentence. For instance, in (10a) the object is omwana 'baby' and in (10b) the object marker is -mu-. The object omwana 'baby' cannot co-occur with the object marker - mu- in (10c) above. The object marker in (10b) incorporates the nominal object onto the verb leading to the obligatory deletion. In case we want to indicate that the object marked by -mu- is omwana and not any other a question can be asked like;

11) *a. wina-ou-la-singa omwana?

who-will-FUT-wash baby?

'Who will wash baby?'

b. a-la-mu-singa

3SG-FUT-him/her-wash

'He/she will wash him/her'

In (10a), both the nominal subject and object are not incorporated in the verb. Example (10c) is ungrammatical due to the occurrence of the object prefix -mu- and nominal object omwana 'baby' in the same sentence.

\section{The Present Tense in Lutsotso}

The present tense usually indicates events that are going on in the present time. Walker $(2013, \mathrm{p} .88)$ adds that the present tense marked by a zero morpheme is found in many Bantu languages of the Great Lakes. In her study, Timbwah observed that the simple present tense is marked by a zero morpheme as a prefix in Lunyole, a language closely related to Lutsotso. Lutsotso marks the present tense non-overtly with a zero morpheme $(\varnothing)$. The person and tense markers are prefixed to the verb root.

Example (12a) illustrates present tense marked by zero morpheme while $12 \mathrm{~b}$ and $12 \mathrm{c}$ illustrates present continuous tense.

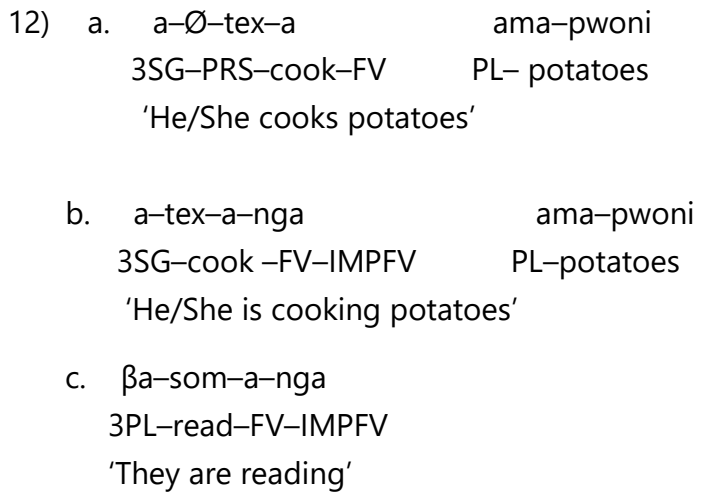

In example (12a) the present tense is marked by a zero morpheme while in (12b) and (12c) --nga is suffixed on the verb atexa and Basoma, respectively, as an imperfective marker of a present occurrence. 


\section{Past Tense}

Past tense in Lutsotso occurs in four degrees as follows: Immediate past, near past, intermediate past and far past tense. Immediate past tense is a simple past tense indicating something that has just happened while the near past means an action has taken place not long ago (yesterday). Intermediate past means few days ago, more than a day and less than a week ago and finally, far (remote) past means long time ago, some days, months or years ago.

The past tense in Lutsotso is marked by ja- which is also the subject agreement marker. The adverbials for time help to specify the exact time as shown in (13):

13) a. ja-texa e-mioko

$$
\text { 3SG[PT]-cooked PL- cassava }
$$

'He/she cooked cassava'

b. Ja-lola i-ngwe omwaka kwawa

3SG[PST] saw SG-leopard year last

'He/she saw a leopard last year'

In (13a) and (13b) above, ja- is the third person subject marker and the past tense marker. In (13b), the adverbial of time is omwaka kwawa 'last year' is used to specify the exact time in the past.

\section{1 Immediate Past}

This is a simple past tense indicating something that has just happened. It is formed from the subject agreement marker plus $x a-$ which is prefixed to the verb stem as (14) indicates:

14) a. nda- xa- $\beta u k u l-a$

ISG-IPT-take-FV

'I have just taken'

b. ja-xe-ts-a ßulano

3SG-IPT-come-FV now

'He/she has just come now'

The immediate past tense in Lutsotso is only used when there is a stress on the fact that the action has taken place just now. In (14b) the $-x a$ - marker emphasizes the fact that he/she was not there a short time previously.

\subsection{Near Past}

As noted earlier, near past refers to an action that has taken place not long ago (yesterday). Near past is marked on the verb by the infix -il-which is placed between the verb root and the final vowel as shown in 15 below.

15) a. omwa-na a- $\varnothing-$ lia oßusuma

SM-child 3SG-PRS-eat ugali

'The child eats ugali' (present tense)

b. omwa-na a-li-il-e oßusuma

SM-child 3SG-NPST-eat-FV ugali

'The child has eaten ugali' 
In (15a) above we have a zero-morpheme to indicate the present tense while in (15b) the suffix -il- is placed between the verb root and the final vowel to indicate the near past tense.

\subsection{Intermediate Past}

Intermediate past - means few days ago (some time past today), more than a day less than a week ago. Intermediate past is shown by use the person marker ja- and the suffix -il- which is placed between the verb root and the final vowel as 16 indicates:

16) a. ja-som-il-e

3SG-read-INT.PST-FV

'He/she read'

b. ja-lim-il-e omu-kunda

3SG-dig-INT.PST-FV SG-field

'He/she dug the field'

In example (16a) above the person marker ja- which is attached to the verb root -som- is used to mark intermediate past tense together with the infix -il- which is placed between the verb root and the final vowel. In (16b) the person marker ja- is attached to the verb root -lim - to mark the past tense and then together with the infix -il-placed between the verb root and the final vowel the intermediate past tense is marked.

\subsection{Far (remote) Past}

Far (remote) past tense is used to indicate events or situations which took place long time ago, some days, months or years ago (Comrie, 1985, p. 6). Far past tense is marked by the person marker ja-in singular and $\beta a$ - in plural as (17a) and (17b) illustrate:

17) a. ja-lol-a imßwa

3SG: FPST-see-FV dog

'He/she saw a dog'

b. $\quad$ a-lol-a imßwa

3PL: FPST-see-FV dog

'They saw a dog'

In example 17, the person marker $j a$ - is prefixed to the verb root -lol- to mark the far past tense in singular while $\beta a-$ is used in plural.

\section{Future Tense in Lutsotso}

The future tense identifies situation that take place after the present moment. Shopen (1995, p. 204) mentions that 'The future is used for events subsequent to the speech moment." Lutsotso distinguishes four categories of future,

Immediate future $=$ few moments, minutes, hours to the action

Near future $=$ The near future tense in Lutsotso shows events or actions that are intended to take place between today and tomorrow

Intermediate future = time ranging from a time more than a day but less than a week.

Remote future $=$ unforeseeable. 


\subsection{Immediate Future Tense}

Immediate Future tense indicates situations that are predicted to take place a moment after now to sunset of the same day of speaking. The prefix la- attached to the verb stem marks this tense as exemplified in (18) below:

18) a. a-la-tex-a efilißwa

3SG-FUT-cook-FV food

'He/she will cook food'

b. o-la-tex-a efilißwa

2SG-FUT-cook-FV food

'You will cook food'

In example (18a) and (18b) above, the prefix -la- is attached to the verb stem -tex- to mark the immediate future tense.

\subsection{Near future tense}

The near future tense in Lutsotso shows events or actions that are intended to take place between today and tomorrow. In the near future, instead of the final $-a$ - the verb ending is $-e-$. In addition, the suffix $-n a$ is put before the subject agreement marker as 19 illustrates:

19) a. a-som-a

$$
\text { e } \int i t a \beta u
$$

3SG/PRES-read-FV

book

'He/she reads a book'

$$
\text { ejitaßu }
$$

SM-boy FUT-3SG-read-FV book

'The boy will read a book'

To mark the near future tense the final vowel changes from -a to -e as illustrated in (19a) and (19b) above. In addition, the suffix -na has been placed before the subject agreement marker $a-$.

\subsection{Intermediate future tense}

In Lutsotso, intermediate future tense indicates a time roughly more than a day but less than a week ahead. The intermediate future tense marker is - axa- with final vowel of the verb changed from ' $a$ ' to ' $e$ ' as exemplified in (20) below:

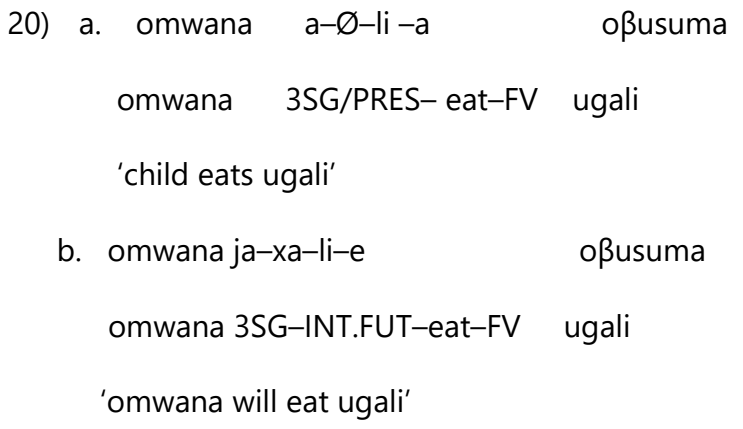

In example (20b) above, the intermediate future tense marker $x a$ - prefix which is preceded by the person marker ja- marks the intermediate future tense. 


\subsection{Remote Future Tense (distant future tense)}

The distant future tense marks events or situations that occur in the unknown or unspecified far future. The distant future is marked on the verb by the prefix li-. which is placed between the subject marker and the root of the verb as in (21) below:

$\begin{array}{lr}\text { 21) a. ndi-li-its-a } & \text { ingo } \\ \text { 1SG-REM.FUT-come-FV home } & \text { 'I will come home' } \\ \text { b. o-li-its-a } & \text { ingo } \\ \text { 2SG-REM FUT-come-FV home } \\ \text { 'You will come home' } \\ \text { c. a-li-its-a } \\ \text { 3SG-REM FUT-come-FV home } \\ \text { 'He/she will come home' }\end{array}$

In (21a), the 1SG subject marker (SM) is $a$ - in (19b) the 2SG subject marker is 0 - and in (21c) the 3SG subject marker is ndi-. The root of the verb-itsa- 'come' is -its- in (21a), (21b) and (21c) and infix -li- marks the remote future tense.

\section{Conclusion}

This paper discussed tense in Lutsotso and its morphological realisation on the verb. From the analysis, it has been established that Lutsotso has a tense system of basic tenses. These include: past, present and future. In addition, the language has a subdivision of its time line in accordance with its interpretation of the time frame. The morphological tense marking discussed has a syntactic as well as a semantic effect related to time on sentences. Lutsotso marks the present tense with a zero morpheme. The agreement markers are prefixed to the verb root. -nga is suffixed on the verb to mark present continuous tense.

The past tense in Lutsotso is marked by ja-which is also the subject agreement marker. The adverbials for time help to specify the exact time. The past tense in Lutsotso occurs in immediate, near, intermediate and far (remote) past tense. Immediate past is formed from the subject agreement marker plus $x a$ - which is prefixed to the verb stem. Near past is marked on the verb by the infix -il- which is placed between the verb root and the final vowel. Intermediate past is shown by use the person marker ja- and the infix -il- which is placed between the verb root and the final vowel. Far past tense is marked by the person marker ja- in singular and $\beta a$ - in plural.

Future tense in Lutsotso occurs in immediate, near, intermediate and far (remote) future tense. Immediate future is marked by the infix -la- attached to the verb stem. In the near future, instead of the final $-a$ - the verb ending is $-e$ - and the suffix -na is put before the subject agreement marker. The intermediate future tense marker is -axa- with final vowel of the verb changed from ' $a$ ' to ' $e$ '. The remote/far/distant future is marked on the verb by the infix -li-. which is placed between the subject marker and the root of the verb. Alongside morphological tense marking, lexical tense marking explains the use of temporal adverbials like mukam $\beta a$ 'tomorrow', to express tense alongside a time axis. The past and future adverbials of time play a major role in expressing past and future tenses by identifying the exact time when an event happens. 


\section{References}

[1] Achesa, R., Mandillah, L. \& Barasa, D., The role of Lwidakho on English word stress perception and production. International Journal of Linguistics, Literature and Translation, 2(6), 262-267.

[2] Angogo, R. (1983). Unity in diversity" A linguistic survey of the Abaluyia of Western Province. Afro-Publishers.

[3] Appleby, L. L. (1961). First Luya Grammar with Exercises. The East African Literature Bureau.

[4] Barasa, D. (2015). The Inflectional forms of Tense and Aspect in Ateso, The University of Nairobi Journal of Language and Linguistics, (4) 82102.

[5] Eberhard, D. M., Simons, G. F., \& Fennig, C. D. (Eds.). 2019. Ethnologue: Languages of the World. (Twenty-second edition). SIL International. Retrieved from http://www.ethnologue.com, 22-12-2020.

[6] Comrie, B. (1985). Tense. Cambridge University Press.

[7] Crystal, D. (1997). A dictionary of linguistics and phonetics (Vol. 30). John Wiley \& Sons.

[8] Gatamu D. (2014) Morphosyntactic Verb Inflections for Tense and Aspect in Kimbeere

[9] Kioko, A. (2005). Theoretical issues in the Grammar of Kikamba: A Bantu Language. Lincom Europa.

[10] Osore, E. (2009). An Analysis of the Internal Structure of Lutsotso Noun Phrase. [Unpublished M.A Dissertation]. Maseno University.

[11] Osore, E. (2017). A Syntactic Analysis of Argument Licensing in Lutsotso Sentence. [Unpublished PhD Dissertation]. Maseno University.

[12] Van Riemsdijk, H., \& Williams, E. (1986). 1986: Introduction to the theory of grammar. MIT Press.

[13] Shopen, T. (1995). Language Typology and Syntactic Description: Volume 3 (Vol. 3). Cambridge University Press.

[14] Sikuku, J. (1998). The morphosyntactic structure of Lubukusu anaphoric relations. Government and Binding Approach. Unpublished M.A. Thesis, Moi University.

[15] Timbwah, S. B. (2011). Morphosyntactic Verb Inflection for Tense and Aspect in Lunyore: A Minimalist Approach. [Unpublished M. A. Dissertation]. Nairobi: University of Nairobi.

[16] Walker, B. J. (2013). Comparative Tense and Aspect in the Mara Bantu Languages: Towards a Linguistic History. [PhD Thesis]. Trinity Western University. 